Cytogenet Genome Res 112:180A (2006) DOI: $\underline{10.1159 / 00087533}$

\section{Assignment of the bovine BCL2-like 2 gene (BCL2L2) to BTA10q15 $\rightarrow$ q21 by in situ hybridization and with somatic cell hybrids}

I. Martín-Burriel, a J. Lyahyai, ${ }^{\text {a P. Zaragoza, }}{ }^{\text {a R.M. Brunner, }}{ }^{\mathrm{b}}$ J.E. Womack, ${ }^{c}$ T. Goldammer ${ }^{\mathrm{b}}$

${ }^{a}$ Laboratorio de Genética Bioquímica, Facultad de Veterinaria (INGEN, I3A), Universidad de Zaragoza, Zaragoza (Spain);

${ }^{b}$ Research Unit Molecular Biology, Research Institute for the Biology of Farm Animals Dummerstorf (FBN), Dummerstorf (Germany);

${ }^{c}$ Department of Veterinary Pathobiology, Texas A\&M University, College Station, TX (USA)

Cytogenet Genome Res 112:180B (2006)

DOI: $\underline{10.1159 / 000087534}$

\section{Assignment of cellular retinoic acid- binding protein 1 (CRABP1) and 2 (CRABP2) to porcine chromosome} $7 q 12 \rightarrow q 23$ and $4 q 21 \rightarrow$ q23 by somatic cell and radiation hybrid panel mapping

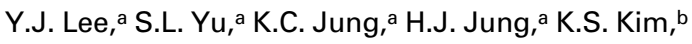

C.S. Park, ${ }^{a}$ D.I. Jin, ${ }^{\text {a J.H. Lee }}{ }^{\mathrm{a}}$

a Division of Animal Science and Resources, Research Center for Transgenic Cloned Pigs (RCTCP), Chungnam National University,


University, Chungju (Korea)
Cytogenet Genome Res 112:180C (2006)

DOI: $10.1159 / 000087535$

\section{Assignment of BReast Cancer Associated 1 (BRCA1) to tammar wallaby (Macropus eugenii) chromosome $2 q 3$ by in situ hybridization}

M.J. Wakefield, a A.E. Alsop ${ }^{b}$

a Division of Immunology and Genetics, John Curtin School of Medical Research, and ${ }^{\mathrm{b}}$ The ARC Centre for Kangaroo Genomics, Research School of Biological Science, The Australian National University, Canberra (Australia) 